\title{
ОЦЕНКА ЛЕГКОЛЕТУЧИХ ОРГАНИЧЕСКИХ СОЕДИНЕНИЙ В ДИАГНОСТИКЕ ХЛАМИДИОЗА
}

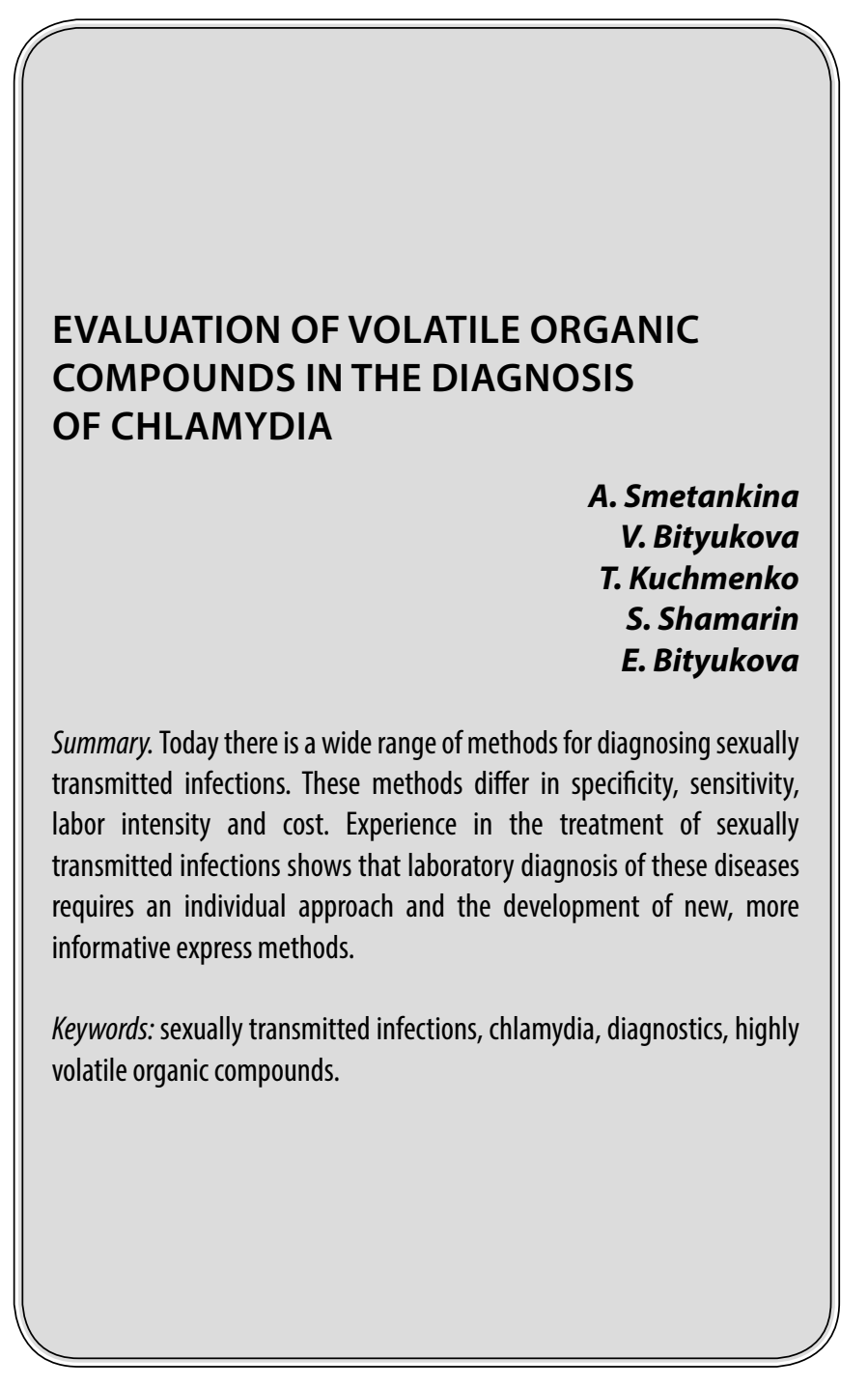

Це^ь

И сследовать легколетучие органические соединения различных классов, характерных для определенного вида инфекций, передающихся половым путем (ИППП).

\section{Материал и методы}

В исследование включены 55 пациенток. Все пациентки были обследованы общеклинически, специфическое обследование на наличие бактериальной и/или вирусной инфекции проводилось с использованием следующих методов:
Сметанкина Анастасия Васильевна

Преподаватель-исследователь, Воронежский государственный медицинский университет им. Н.Н. Бурденко zhuchkova954@yandex.ru

Битюкова Валерия Витальевна Д.м.н., Воронежский государственный медицинский университет им. Н.Н. Бурденко bityukovavv@yandex.ru

Кучменко Татьяна Анатольевна

Д.х.н., профессор, Воронежский государственный университет инженерных технологий tak1907@mail.ru

Шамарин Станислав Вячеславович К.м.н., доцент, Воронежский государственный медицинский университет им. Н.Н. Бурденко shamarin-med@yandex.ru

Битюкова Елизавета Алексеевна Воронежский государственный университет инженерных технологий bityukovaelizaveta@gmail.ru

Аннотация. На сегодняшний день имеется широкий спектр методов диагностики инфекций, передающихся половым путем. Данные методы отличаются между собой по специфичности, чувствительности, трудоемкости и стоимости. Опыт лечения инфекций, передающихся половым путем, свидетельствует, что лабораторная диагностика этих заболеваний требует индивидуального подхода и разработки новых, более информативных экспресс-методов.

Ключевые слова: инфекции, передающиеся половым путем, хламидиоз, диагностика, легколетучие органические соединения.

1. Микроскопический - бактериоскопия мазка отделяемого из цервикального канала и влагалища;

2. Культуральный (посев) - с автоматическим подсчетом на автоматизированном бактериологическом анализаторе с выделением механизмов резистентности;

3. Серологический - иммуноферментный анализ;

4. Молекулярно-биологический - полимеразная цепная реакция (ПЦР) в режиме реального времени.

Пациенток разделили на 2 группы. Основная группа - 25 пациенток, имеющих ИППП (хламидийную инфекцию), средний возраст составил $32,7 \pm 3,2$ лет, наличие 
Таблица 1. Газы-маркеры тестируемых заболеваний [8-14]

\begin{tabular}{|l|l|l|l|}
$\begin{array}{l}\text { № } \\
\text { n/п }\end{array}$ & Запах выделений & $\begin{array}{l}\text { Определяемые } \\
\text { газы-маркеры в РГФ }\end{array}$ & $\begin{array}{l}\text { Диагностическое } \\
\text { Заключение }\end{array}$ \\
\hline 1 & Отсутствует & Оксикислоты & Норма \\
\hline 2 & Дрожжевой & $\begin{array}{l}\text { Одноатомные спирты, альдегиды, } \\
\text { карбоновые кислоты }\end{array}$ & Кандидоз \\
\hline 3 & Рыбный & Алифатические амины, изонитрилы & Гарднереллез \\
\hline 4 & Отсутствует & Одноатомные спирты & Хламидиоз \\
\hline 5 & Неприятный & Алифатические и ароматические амины & Трихомониаз \\
\hline 6 & Отсутствует & Не определены & Микоплазмоз \\
\hline 7 & Отсутствует & Не определены & Уреаплазмоз \\
\hline 8 & Отсутствует & Не определены & Вирус папилломы человека \\
\hline
\end{tabular}

хламидийной инфекции подтверждено лабораторными методами. Контрольная группа - 30 клинически здоровых женщин, средний возраст - 27,9 \pm 1,8 года.

Всем пациенткам проводили исследование биопроб для изучения состава равновесной газовой фазы (РГФ) над цервикальной слизью.

\section{Результаты и обсужАение}

Многие возбудители ИППП, размножаясь в питательной среде слизистых оболочек внутренних половых органов, выделяют в процессе своей жизнедеятельности легколетучие органические соединения различных классов, в том числе спирты, альдегиды, карбоновые кислоты, алифатические и ароматические амины и др. Данные соединения можно считать газами-маркерами, присутствие которых в исследуемой пробе свидетельствует о развитии заболевания [1,2]. Обнаружить легко- летучие органические соединения в биологических пробах можно различными методами [3-7]. Для наиболее часто диагностируемых ИППП характерны индивидуальные запах выделений и состав РГФ над ними (табл. 1).

\section{Зак^ючение}

Одним из путей реализации диагностирования ИППП является применение инновационных разработок, сочетающих в себе простоту методики анализа и принятия решения в сочетании с высокой чувствительностью и специфичностью. Данные микробиологического исследования и ПЦР подтверждены полученными результатами при использовании предлагаемого метода. Для диагностики ИППП возможно использование метода пьезокварцевого микровзвешивания, основанного на селективном поглощении газов-маркеров ИППП тонкими высокоспецифичными пленками - модификаторами пьезокварцевых резонаторов.

\section{ЛИТЕРАТУРА}

1. Кучменко Т.А., Шуба А.А., Тюркин И.А, Битюкова В.В. Оценка состояния биологических проб по составу равновесной газовой фазы с применением мультисенсорной системы // Журн. аналит. химии. 2014. Т. 69. № 5. С. 534.

2. Weiss T., Angerer J. Simultaneous determination of various aromatic amines and metabolites of aromatic nitro compounds in urine for low level exposure using gas chromatography-mass spectrometry // J. Chromatogr. B. 2002. V. 778. № 1-2. P. 179.

3. Deng Y.-H., Wang H., Zhong L., Zhang H.-S. Trace determination of short-chain aliphatic amines in biological samples by micellar electrokinetic capillary chromatography with laser-induced fluorescence detection // Talanta. 2009. V. 77. № 4. P. 1337.

4. Rudnicka J., Kowalkowski T., Ligor T., Buszewski B. Determination of volatile organic compounds as biomarkers of lung cancer by SPME-GC-TOF/MS and chemometrics // J. Chromatogr. B. 2011. V. 879. № 30. P. 3360.

5. Senthilmohan S.T., Kettle A.J., McEwan M.J, Dummer J., Edwards S.J., Wilson P.F., Epton M.J. Detection of monobromamine, monochloramine and dichloramine using selected ion flow tube mass spectrometry and their relevance as breath markers // Rapid Commun. Mass Spectrom. 2008. V. 22. № 5. P. 677.

6. Carrola J, Rocha C.M., Barros A.S., Gil A.M., Goodfellow B.J., Carreira I.M., Bernardo J., Gomes A., Sousa V., Carvalho L., Duarte I.F. Metabolic signatures of lung cancer in biofluids: NMR-based metabonomics of urine // J. Proteome Res. 2011. V. 10. № 1. P. 221.

7. Gardner J.W., Shin H.W., Hines E.L. An electronic nose system to diagnose illness // Sens. Actuators B: Chem. 2000. V. 70. № 1-3. P. 19.

8. Revelsky A.I., Revelsky I.A., Miller B., Oriedo V. Simultaneous determination of fatty, dicarboxylic and amino acids based on derivatization with isobutyl chloroformate followed by gas chromatography — positive ion chemical ionization mass spectrometry //J. Chromatogr. B. 2004. V. 800. № 1-2. P. 101. 
9. Сухарев А., Ермолаева Т.Н., Беда Н.А., Мамаева С.А., Ермолаев В.Г. Иммунохимическое исследование лактоферрина, продуктов деградации фибриногена, иммуноглобулинов и белковых фракций в смешанной слюне перспективный неинвазивный тест в оценке состояния здоровья при диспансеризации // Современные наукоемкие технологии. 2006. № 6. С. 79.

10. Pavlou A.K., Magan N., McNulty C., Jones J.M., Sharp D., Brown J., Turner A.P.F. Use of an electronic nose system for diagnoses of urinary tract infections// Biosens. Bioelectron. 2002. V. 17. № 10. P. 893.

11. Bernabei M., Pennazza G., Santonico M., Corsi C., Roscioni C., Paolesse R., Di Natale C., D'Amico A. A preliminary study on the possibility to diagnose urinary tract cancers by an electronic nose // Sens. Actuators B: Chem. 2008. V. 131. № 1. P. 1.

12. Бельский В.Е. Солюбилизация газов и насыщенных паров в биологических средах // Хим.-фарм. журнал. 2000. Т. 34. № 11. С. 42.

13. Buszewski B., Ulanowska A., Kowalkowski T., CieslinskiK. Identification of volatile lung cancer markers by gas chromatography-mass spectrometry: Comparison with discrimination by canines // Anal. Bioanal. Chem. 2012. V. 404. № 1-2. P. 141.

14. Gaspar E.M., Lucena A.F., Duro da Costa J., Chavesdas Neves H. Organic metabolites in exhaled human breath - A multivariate approach for identification of biomarkers in lung disorders // J. Chromatogr. A. 2009. V. 1216. № 14. P. 2749.

( С Сметанкина Анастасия Васильевна ( zhuchkova954@yandex.ru ), Битюкова Валерия Витальевна ( bityukovavv@yandex.ru ),

Кучменко Татьяна Анатольевна ( tak1907@mail.ru ), Шамарин Станислав Вячеславович ( shamarin-med@yandex.ru ),

Битюкова Елизавета Алексеевна ( bityukovaelizaveta@gmail.ru ).

Журнал «Современная наука: актуальные проблемы теории и практики»

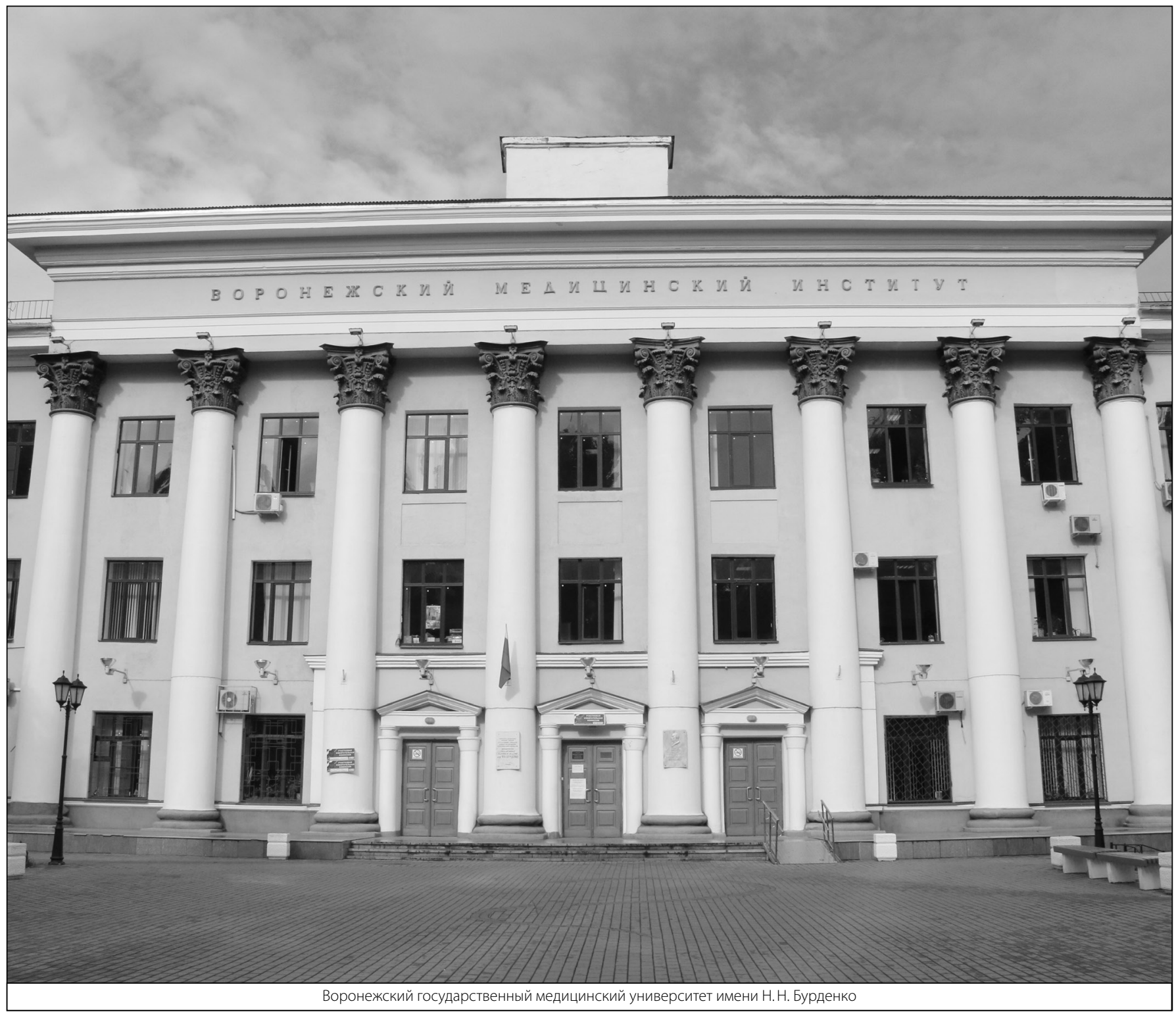

